\title{
Assessment of the Glutenin Subunits Diversity in a Durum Wheat (T. turgidum ssp. durum) Collection from Morocco
}

\author{
Youssef Chegdali ${ }^{1,2}$, Hassan Ouabbou ${ }^{1}{ }^{1}$, Abdelkhalid Essamadi ${ }^{2}$, Fausto Cervantes ${ }^{3}$, \\ Maria Itria Ibba ${ }^{3}$ (D) and Carlos Guzmán ${ }^{4, *(\mathbb{D})}$ \\ 1 Laboratory of Gene Bank, Crop Physiology and Genetic Resources, Institute National de la Recherche \\ Agronomique (INRA), Settat, B.P. 589, 26000 Settat, Morocco; youssefchegdali89@gmail.com (Y.C.); \\ ouabbou@yahoo.com (H.O.) \\ 2 Laboratory of Biochemistry and Neuroscience, Applied Biochemistry and Toxicology Team, \\ Faculty of Sciences and Technology, Hassan 1st University, P.O. Box 577, 26000 Settat, Morocco; \\ essamadi@uhp.ac.ma \\ 3 Global Wheat Program, CIMMYT, Km 45 Carretera, México-Veracruz, El Batán, C.P. 56130 Texcoco, \\ Estado de México, Mexico; faustocer@hotmail.com (F.C.); m.ibba@cgiar.org (M.I.I.) \\ 4 Departamento de Genética, Escuela Técnica Superior de Ingeniería Agronómica y de Montes, \\ Edificio Gregor Mendel, Campus de Rabanales, Universidad de Córdoba, CeiA3, ES-14071 Córdoba, Spain \\ * Correspondence: carlos.guzman@uco.es
}

Received: 12 June 2020; Accepted: 30 June 2020; Published: 3 July 2020

\begin{abstract}
Landraces and old wheat cultivars display great genetic variation and constitute a valuable resource for the improvement of modern varieties, especially in terms of quality. Gluten quality is one of the major determinants of wheat quality, and it is greatly influenced by variation in the high molecular weight and low molecular weight glutenin subunits (HMW-GS and LMW-GS). Identification of novel allelic variants for either of the two groups of the gluten-forming proteins could greatly assist in the improvement of wheat gluten quality. In the present study, the allelic composition of the HMW- and LMW-GS of ninety-five durum wheat accessions was evaluated. These accessions included Moroccan cultivars and landraces and North American cultivars and were all conserved in the National Gene Bank from Morocco. In total, 20 cataloged alleles and 12 novel alleles were detected. For the HMW-GS, two alleles were found at the Glu-A1 locus, and seven different allelic variants were identified at the Glu-B1 locus. Among them, two alleles were new (alleles Glu-B1cp and $c o$ ). Additionally, two of the analyzed accessions exhibited the Glu-D1d allele, suggesting the presence of the Glu-D1 locus introgression. For the LWM-GS, eight, ten and two alleles were identified at the $G l u-A 3, G l u-B 3$ and Glu-B2 loci, respectively. Among them, two new allelic variants were identified at the Glu-A3 locus, and seven new allelic variants were identified at the Glu-B3 locus. Overall, the Moroccan landraces exhibited a greater genetic diversity and a greater number of glutenin alleles compared to the Moroccan and North American durum wheat cultivars. The novel germplasm and glutenin alleles detected in this study could contribute to the improvement of durum wheat quality and the expansion of modern durum wheat genetic diversity.
\end{abstract}

Keywords: glutenin subunits; durum wheat; SDS-PAGE analysis; genetic diversity; durum landraces

\section{Introduction}

Durum wheat (Triticum turgidum ssp. durum; $\mathrm{A}^{\mathrm{u}} \mathrm{A}^{\mathrm{u}} \mathrm{BB} ; 2 \mathrm{n}=4 \mathrm{x}=28$ ) is one of the first domesticated crops in the world. It derived from the T. turgidum ssp. dicoccum (emmer wheat), which in turn resulted from the domestication of T. turgidum ssp. dicoccoides (wild emmer). Wild emmer, in turn, 
originated from the hybridization of two different wild species: T. urartu (donor of the $\mathrm{A}^{\mathrm{u}}$ genome) and Aegilops speltoides (donor of the B genome) [1]. According to archeological evidences, the domestication of wild emmer, its evolution into durum wheat and its use for the preparation of food all started around 10,000 years ago in the fertile crescent area [1]. Subsequently, durum wheat spread in the Mediterranean Basin lands where, starting around 2000 ago, it became one of the major staple crops of that region. Currently, about 18 million hectares are devoted to the cultivation of durum wheat, with Europe, Canada, North Africa, Turkey, USA, Mexico, Kazakhstan, India and Syria being the major durum wheat producers. In the Mediterranean Basin area, durum wheat represents more than $50 \%$ of the total wheat-growing area, and it is used for the preparation of a wide variety of foods such as pasta, couscous and bread. In Morocco especially, durum wheat is particularly important, and around one million hectares are dedicated to its cultivation [2,3]. However, the country is still among the first six countries importing durum wheat [4]. For this reason, Moroccan breeding programs have the challenge of developing novel materials with an increased productivity and desirable end-use quality to cover the demand of the national consumers.

New genetic resources are fundamental for breeding programs, as they host the necessary genetic variability to continue progressing in the development of novel varieties. Morocco is one of the major centers of durum wheat genetic diversity [5], and a multitude of durum wheat traditional varieties or landraces have been developed through either natural or farmers selection. These precious resources are now mostly conserved in Germplasm Banks. Several studies have found a high variability in the durum Moroccan landraces and claimed that this material should be used in breeding programs for the introgression or improvement of desirable traits [6-8]. In particular, landraces could be used to improve, among the others, the grain nutritional and processing quality $[9,10]$. Currently, wheat landraces are still grown in several areas (mainly rural), and their organoleptic and processing quality for the production of local homemade products are often considered superior when compared to modern wheat varieties [11,12]. For this reason, understanding the components present in the landraces, which contribute to their processing and end-use quality, is of fundamental importance in order to exploit their genetic variability and more efficiently transfer these desirable traits into more productive modern varieties.

Gluten is one of the major factors affecting wheat end-use quality, conferring the unique viscoelastic properties to wheat dough. Gluten is formed after the flour is mixed with water and is constituted of approximately the same quantity of glutenins and gliadins, two classes of the wheat seed storage proteins. The glutenins constitute the polymeric part of gluten, and their variation has been associated with great differences in the physicochemical and rheological properties of the dough (elasticity and extensibility). According to their mobility in a sodium dodecyl sulfate-polyacrylamide gel electrophoresis (SDS-PAGE), the glutenins are divided into two classes: the low-molecular-weight glutenin subunits (LMW-GS) and high-molecular-weight glutenin subunits (HMW-GS) [13]. The HMW-GS are encoded by genes located at the Glu-A1 and Glu-B1 loci, on the long arm of the homoeologous group 1 chromosomes [14-16]. In contrast, the LMW-GS are encoded by genes located at the Glu-A3, Glu-B3 and Glu-B2 loci, located on the short arm of the homoeologous group 1 chromosome $[10,17]$. Several studies have shown that variation in the HMW- or LMW-GS alleles is associated with differences in the gluten and end-use quality [9,18-21]. For this reason, the study of the glutenins' composition is fundamental to understanding and characterizing gluten quality. Durum wheat landraces exhibit a wide variability of this class of proteins, and, in the past years, several sets of landraces from different Mediterranean countries have been characterized for their HMW- and LMW-GS profile [10,19,20,22-24].

In this context, the present work was conducted to evaluate the variability of the HMW-GS and LMW-GS composition in a set of durum wheat accessions conserved in the Moroccan National Gene Bank. The results of this study will help expand the knowledge on the glutenin allelic variation, which could then be exploited to improve the quality of modern durum wheat varieties and their genetic variability. 


\section{Material and Methods}

\subsection{Plant Material}

The study was conducted using a durum wheat collection from the National Gene Bank from Morocco (MGB), consisting of 52 Moroccan landraces, 14 Moroccan modern cultivars and 29 North American (Canada and United States) modern cultivars (Electronic Supplementary Table S1). The grains of each accession used for the SDS-PAGE analysis were obtained from a single spike. Apart from these accessions, the following cultivars were used as reference samples for specific glutenins alleles in the SDS-PAGE analysis: Pitic, Shan 229, CI-12213 (Triticum dicoccum), Langdon, Wilbur, Opata, Pavon, Cocorit, Andalusia, Fanfarron, BC and Ardente. The grains of these cultivars were all obtained from the International Maize and Wheat Improvement Center (CIMMYT) Germplasm Bank.

\subsection{Electrophoretic Analysis}

The electrophoretic analysis (1D SDS-PAGE) was carried out according to the method of the Laboratory of Wheat Chemistry and Quality of CIMMYT [25]. Ten grains of each accession were grounded, and after, $20 \mathrm{mg}$ of the whole-meal flour was used for the extraction of the glutenins. The whole meal flour was incubated with $0.75 \mathrm{~mL}$ of $50 \%$ propanol $(v / v)$ for $30 \mathrm{~min}$ in a Thermomixer (Eppendorf, Germany) at 1400 r.p.m. and $65^{\circ} \mathrm{C}$ to extract the gliadins. The tubes were centrifuged 2 min at 10,000 r.p.m. The supernatant containing the gliadins fraction was discarded. The same process was repeated to remove any remaining gliadins. $100 \mu \mathrm{L}$ of a solution with DTT at $1.5 \%(w / v)$ formed with $50 \mu \mathrm{L}$ of propanol at $50 \%(v / v)$ and $50 \mu \mathrm{L}$ of Tris- $\mathrm{HCl} 0.08 \mathrm{M} \mathrm{pH} 8.0$, were added to the pellet. The tubes were mixed in a vortex and incubated for $30 \mathrm{~min}$ in a Thermomixer at 1400 r.p.m. and $65^{\circ} \mathrm{C}$. Following this, the tubes were centrifuged $2 \mathrm{~min}$ at 10,000 r.p.m., and $100 \mu \mathrm{L}$ of a solution with vinylpyridine at $1.4 \%(v / v)$ formed with $50 \mu \mathrm{L}$ of propanol at $50 \%(v / v)$ and $50 \mu \mathrm{L}$ Tris- $\mathrm{HCl} 0.08 \mathrm{M}$ $\mathrm{pH} 8.0$ were added. The tubes were mixed in a vortex and incubated for $15 \mathrm{~min}$ in a Thermomixer at 1400 r.p.m. and $65^{\circ} \mathrm{C}$, and after they were centrifuged for $2 \mathrm{~min}$ at 13,000 r.p.m. The supernatant was transferred to a new tube. $180 \mu \mathrm{L}$ of a solution Tris-HCl M pH 6.8, 2\% SDS (w/v), 40\% glycerol (w/v) and $0.02 \%(w / v)$ bromophenol blue were added. The tubes were mixed in a vortex and incubated for $5 \mathrm{~min}$ in a Thermomixer at 1400 r.p.m. and $90^{\circ} \mathrm{C}$, and after they were centrifuged for 2 min at 13,000 r.p.m. $6 \mu \mathrm{L}$ of the supernatant were used for the gels. The separating gel had a concentration of acrylamide of $15 \%$ and was prepared using $1 \mathrm{M}$ Tris buffer with a $\mathrm{pH}$ of 8.0 instead of the conventional $\mathrm{pH} 8.8$. Gels were run at $12.5 \mathrm{~mA}$ per gel for $20 \mathrm{~h}$. The gels were stained using coomassie blue.

The different glutenins subunits were named following the nomenclature of Payne and Lawrence [26] for HMW-GS and Nieto-Taladriz et al. [27] for LMW-GS glutenins.

\subsection{Data Analysis}

Microsoft Excel was used to calculate the allelic frequencies for each locus and for each sub-collection, as well as to assess the genetic diversity $(\mathrm{He})$ and the effective number of alleles $(\mathrm{Ne})$ using the following formulas from Nei [28,29]:

$$
\begin{aligned}
& H e=1-\sum \rho i^{2} \\
& N e=1 / \sum \rho i^{2}
\end{aligned}
$$

where $\rho i$ : frequency of the ith allele in a locus. 


\section{Results}

\subsection{Variability for $H M W-G S$}

A wide variability in the HMW-GS alleles was observed among the analyzed genotypes (Table 1 and Figure 1). Specifically, at the Glu-A1 locus two alleles were detected: the null allele (Glu-A1c), which was present in most of the analyzed materials, and the Glu-A1a allele (subunit 1), which was present only in the Moroccan landrace MGB-16563. Compared to the Glu-A1 locus, the Glu-B1 locus showed a greater polymorphism, and seven different alleles were detected among the landraces and modern cultivars. Among the Moroccan landraces, the alleles Glu-B1b (subunits 7+8), Glu-B1d (subunits $6+8$ ), Glu-B1e (subunits 20+20) and Glu-B1f (subunits 13+16) were identified, all very common in modern wheat varieties. Apart from these, a large percentage (38.5\%) of the accessions in this group also exhibited the rarer allele Glu-B1aq (subunits 32+33) (Figure 1-I, lanes L and M), which was also found in some Algerian durum wheat landraces by Cherdouh et al. [22]. Additionally, two landraces (MGB-2963 and MGB-3152) showed a novel allele that, according to the Wheat Gene Catalogue [30] and the recent publication by Alvarez and Guzmán [31], we propose to name Glu-B1co. This novel allele is constituted by the novel subunit combination $20+22^{*}$ (Figure $1-\mathrm{I}$, lane F). The subunit $22^{*}$ is a rare subunit that was described by Hernandez-Espinosa et al. [9] and that shows a slightly lower mobility than the subunit 22 described first in the bread wheat cultivar 'Wilbur' (Figure 1-I, lane E).

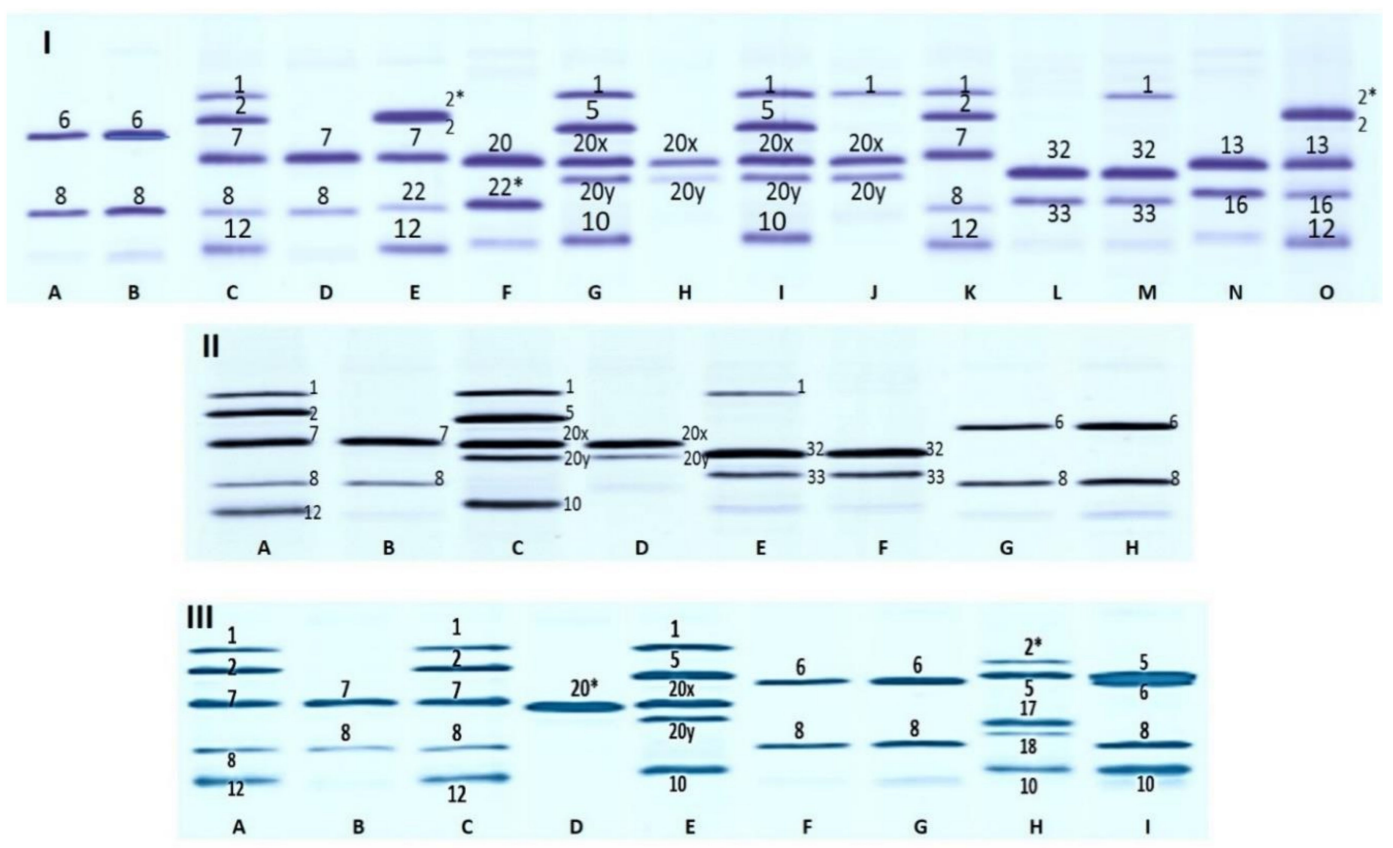

Figure 1. HMW-GS composition observed in a durum wheat collection. I, Moroccan landraces. Lanes are as follow: A, 'Langdon' (Glu-B1 6+8); B, MGB-9327 (Glu-B1 6+8); C and K, 'Pitic' (Glu-A1 1, Glu-B1 7+8, Glu-D1 2+12); D, MGB-9404 (Glu-B1 7+8); E, 'Wilbur' (Glu-A1 2*, Glu-B1 7+22, Glu-D1 2+12); F, MGB-2963 (Glu-B1 20+22*); G and I, 'Shan 229' (Glu-A1 1, Glu-B1 20x+20y, Glu-D1 5+10); H, MGB-3082 (Glu-B1 20x+20y); J, MGB-16563 (Glu-A1 1, Glu-B1 20x+20y); L, MGB-3003 (Glu-B1 32+33); M, CI-12213 (Glu-A1 1, Glu-B1 32+33); N, MGB-5963 (Glu-B1 13+16); O, 'Opata' (Glu-A1 2*, Glu-B1 13+16, Glu-D1 2+12). II, Moroccan cultivars. Lanes are as follow: A, 'Pitic' (Glu-A1 1, Glu-B1 7+8, Glu-D1 2+12); B, MGB-20 (Glu-B1 7+8); C, “Shan 229” (Glu-A1 1, Glu-B1 20x+20y, Glu-D1 5+10); D, MGB-32 (Glu-B1 20x+20y); E, CI-12213 (Glu-A1 1, Glu-B1 32+33); F, MGB-33 (Glu-B1 32+33); G, 'Langdon' (Glu-B1 6+8); H, MGB-34 (Glu-B1 6+8). III, North American cultivars. Lanes are as follow: A and C, 'Pitic' (Glu-A1 1, Glu-B1 7+8, Glu-D1 2+12); B, MGB-66092 (Glu-B1 7+8); D, MGB-66023 (Glu-B1 20*); E, 'Shan 229' (Glu-A1 1, Glu-B1 20x+20y, Glu-D1 5+10); F, 'Langdon' (Glu-B1 6+8); G, MGB-66049 (Glu-B1 6+8); H, Pavon (Glu-A1 2*, Glu-B1 17+18, Glu-D1 5+10); I, MGB-66079 (Glu-B1 6+8, Glu-D1 5+10). 
Table 1. Allelic frequency for each locus of HMW-GS in the durum materials analyzed.

\begin{tabular}{|c|c|c|c|c|c|c|c|c|}
\hline \multirow{2}{*}{ HMW-GS } & \multicolumn{2}{|c|}{ Total } & \multicolumn{2}{|c|}{$\begin{array}{l}\text { Moroccan } \\
\text { Landraces }\end{array}$} & \multicolumn{2}{|c|}{$\begin{array}{l}\text { Moroccan } \\
\text { Cultivars }\end{array}$} & \multicolumn{2}{|c|}{$\begin{array}{c}\text { North American } \\
\text { Cultivars }\end{array}$} \\
\hline & N(95) & $\%$ & $N(52)$ & $\%$ & $\mathrm{~N}(14)$ & $\%$ & $\mathrm{~N}(29)$ & $\%$ \\
\hline \multicolumn{9}{|l|}{ Glu-A1 } \\
\hline$a(1)$ & 1 & 1.1 & 1 & 1.9 & - & - & - & - \\
\hline$c$ (Null) & 94 & 98.9 & 51 & 98.1 & 14 & 100 & 29 & 100 \\
\hline \multicolumn{9}{|l|}{ Glu-B1 } \\
\hline$b(7+8)$ & 17 & 17.9 & 5 & 13.5 & 6 & 42.9 & 4 & 13.8 \\
\hline$d(6+8)$ & 27 & 28.4 & 7 & 9.6 & 3 & 21.4 & 19 & 65.5 \\
\hline$e(20+20)$ & 25 & 26.3 & 17 & 32.7 & 3 & 21.4 & 5 & 17.2 \\
\hline$f(13+16)$ & 1 & 1.1 & 1 & 1.9 & - & - & - & - \\
\hline$a q(32+33)$ & 22 & 23.2 & 20 & 38.5 & 2 & 14.3 & - & - \\
\hline $\operatorname{co}\left(20+22^{*}\right)$ & 2 & 2.1 & 2 & 3.8 & - & - & - & - \\
\hline$c p\left(20^{*}\right)$ & 1 & 1.1 & - & - & - & - & 1 & 3.4 \\
\hline \multicolumn{9}{|l|}{ Glu-D1 ${ }^{1}$} \\
\hline$d(5+10)$ & 2 & 2.1 & - & - & - & - & 2 & 6.9 \\
\hline
\end{tabular}

${ }^{1}$ Glu-D1 is not usually present in durum wheat due to the absence of the D genome. Two accessions developed by chromosome engineering presented this locus in the study.

In contrast, most of the Moroccan modern durum wheat cultivars possessed the alleles Glu-B1b, Glu-B1d, Glu-B1e and Glu-B1f, whereas the rare allele Glu-B1aq was present only in two cultivars.

Similarly to the Moroccan cultivars, most of the modern cultivars from North America also exhibited the alleles Glu-B1b, Glu-B1d and Glu-B1e. One accession of this group (MGB-66023) showed a novel subunit that was not previously described and which was characterized by a slightly higher mobility than the subunit 20 present in the reference bread wheat cultivar 'Shan 229' (Figure 1-III, lanes D and E). We tentatively named this novel subunit $20^{*}$ and the novel allele Glu-B1cp. In addition, two accessions (MGB-66071 and MGB-66079) also showed the unexpected subunits 5+10 (Figure 1-III, lane I), which are encoded by the Glu-D1d allele on the 1D chromosome of bread wheat and which are probably associated with the Glu-D1 locus translocation. The rest of the glutenin profile of these two lines in fact corresponded to that of a typical durum wheat line. Additionally, the identity of these lines was confirmed with the analysis of their grain color and hardness, which confirmed that these two lines were indeed durum wheat lines and not bread wheat lines.

\subsection{Variability for $L M W-G S$}

According to the SDS-PAGE analysis, a wide variability was also identified for the LMW-GS. In total, twenty-one different LMW-GS alleles were detected, eight of which were at the Glu-A3 locus, ten at the Glu-B3 locus and three at the Glu-B2 locus (Table 2). 
Table 2. Allelic frequency for each locus of LMW-GS in the materials analyzed.

\begin{tabular}{|c|c|c|c|c|c|c|c|c|}
\hline \multirow{2}{*}{ LMW-GS } & \multicolumn{2}{|c|}{ Total } & \multicolumn{2}{|c|}{ Moroccan Landraces } & \multicolumn{2}{|c|}{ Moroccan Cultivars } & \multicolumn{2}{|c|}{ North American Cultivars } \\
\hline & $\mathrm{N}(95)$ & $\%$ & $N(52)$ & $\%$ & $\mathbf{N}(14)$ & $\%$ & $N(29)$ & $\%$ \\
\hline \multicolumn{9}{|l|}{ Glu-A3 } \\
\hline$a(6)$ & 40 & 42.1 & 14 & 26.9 & 6 & 42.9 & 20 & 69 \\
\hline$b(5)$ & 10 & 10.5 & 6 & 11.5 & 2 & 14.3 & 2 & 6.9 \\
\hline$c(6+10)$ & 6 & 6.3 & - & - & 1 & 7.1 & 5 & 17.2 \\
\hline$d(6+11)$ & 3 & 3.2 & 1 & 1.9 & - & - & 2 & 6.9 \\
\hline$e(11)$ & 30 & 31.6 & 26 & 50 & 4 & 28.6 & - & - \\
\hline$h$ (null) & 4 & 4.2 & 4 & 7.7 & - & - & - & - \\
\hline$b b(20)$ & 1 & 1.1 & 1 & 1.9 & - & - & - & - \\
\hline$b c\left(5^{* *}\right)$ & 1 & 1.1 & - & - & 1 & 7.1 & - & - \\
\hline Glu-B3 & & & & & - & - & & \\
\hline$a(2+4+15+19)$ & 77 & 81.1 & 40 & 76.9 & 11 & 78.6 & 26 & 89.7 \\
\hline$b(8+9+13+16)$ & 4 & 4.2 & 3 & 5.8 & - & - & 1 & 3.4 \\
\hline$f(2+4+15+17)$ & 1 & 1.1 & - & - & - & - & 1 & 3.4 \\
\hline ah $(8+9+16)$ & 6 & 6.3 & 2 & 3.8 & 3 & 12.4 & 1 & 3.4 \\
\hline$a q(2+4+8+15+19)$ & 2 & 2.1 & 2 & 3.8 & - & - & - & - \\
\hline $\operatorname{ar}(1+3+7+15+18)$ & 1 & 1.1 & 1 & 1.9 & - & - & - & - \\
\hline as $(1+3+8+13+16+19)$ & 1 & 1.1 & 1 & 1.9 & - & - & - & - \\
\hline at $(2+4+17)$ & 1 & 1.1 & 1 & 1.9 & - & - & - & - \\
\hline$a u(2+4+7+15+19)$ & 1 & 1.1 & 1 & 1.9 & - & - & - & - \\
\hline$a v(9+13+16)$ & 1 & 1.1 & 1 & 1.9 & - & - & - & - \\
\hline \multicolumn{9}{|l|}{ Glu-B2 } \\
\hline$a(12)$ & 59 & 62.1 & 26 & 50 & 12 & 85.7 & 21 & 72.4 \\
\hline$b$ (Null) & 35 & 36.8 & 25 & 48.1 & 2 & 14.3 & 8 & 27.6 \\
\hline$d(12.1)$ & 1 & 1.1 & 1 & 1.9 & 6 & 42.9 & - & - \\
\hline
\end{tabular}

The Moroccan landraces showed six, nine and three alleles at the Glu-A3, Glu-B3 and Glu-B2 loci, respectively. At the Glu-A3 locus, half of the accessions possessed the allele Glu-A3e (subunit 11), whereas more than a quarter had the allele Glu-A3a (subunit 6). The alleles Glu-A3b (subunit 5), Glu-A3h (null) and Glu-A3d (subunits 6+11) were present in six, four and one accession, respectively. The accession MGB-16563 had the subunit 20 at this locus (Figure 2, lane H), which was first described by Ruiz et al. [24] in a set of Spanish durum wheat materials. Here, we tentatively propose to name this allele Glu-A3bb. At the Glu-B3 locus, ten different alleles were found among the Moroccan landraces, and the allele Glu-B3a (subunit 6) was the most frequent, being present in $76.9 \%$ of the landraces. Among the rest of the Glu-B3 alleles, the rare allele Glu-B3ah (subunits 8+9+16), previously described by Hernandez-Espinosa et al. [9], was the second most frequent allele and was identified in six different landraces. Two of these accessions showed the combination of subunits $2+4+8+15+19$ (Figure 2, lane I), which was also described by Ruiz et al. [24]. We propose to name this allele Glu-B3aq. In addition, five novel LMW-GS subunit combinations not previously reported in the literature were also found among these landraces: 1+3+7+15+18 (Glu-B3ar) (Figure 2, lane H), 1+3+8+13+16+19 (Glu-B3as) (Figure 2, lane F), 2+4+17 (Glu-B3at) (Figure 2, lane O), 2+4+7+15+19 (Glu-B3au) (Figure 2, lane T) and $9+13+16$ (Glu-B3av). The allele name reported in brackets has been proposed here for the first time, following the instructions reported in the Wheat Gene Catalogue. At the Glu-B2 locus, three different alleles were identified: Glu-B2a (subunit 12), Glu-B2b (null) and a novel allele which was present in the landrace MGB-3125. This last allele possessed one subunit with a slightly higher mobility than the subunit 12 of the check variety 'Cocorit' (Figure 2, lane O) and a slightly lower mobility than the subunit 13 found in the variety 'Fanfarron' (Figure 2, lane K). We propose to name this subunit 12.1 and the associated allele Glu-B2d, according to the order followed in the Wheat Gene Catalogue. 

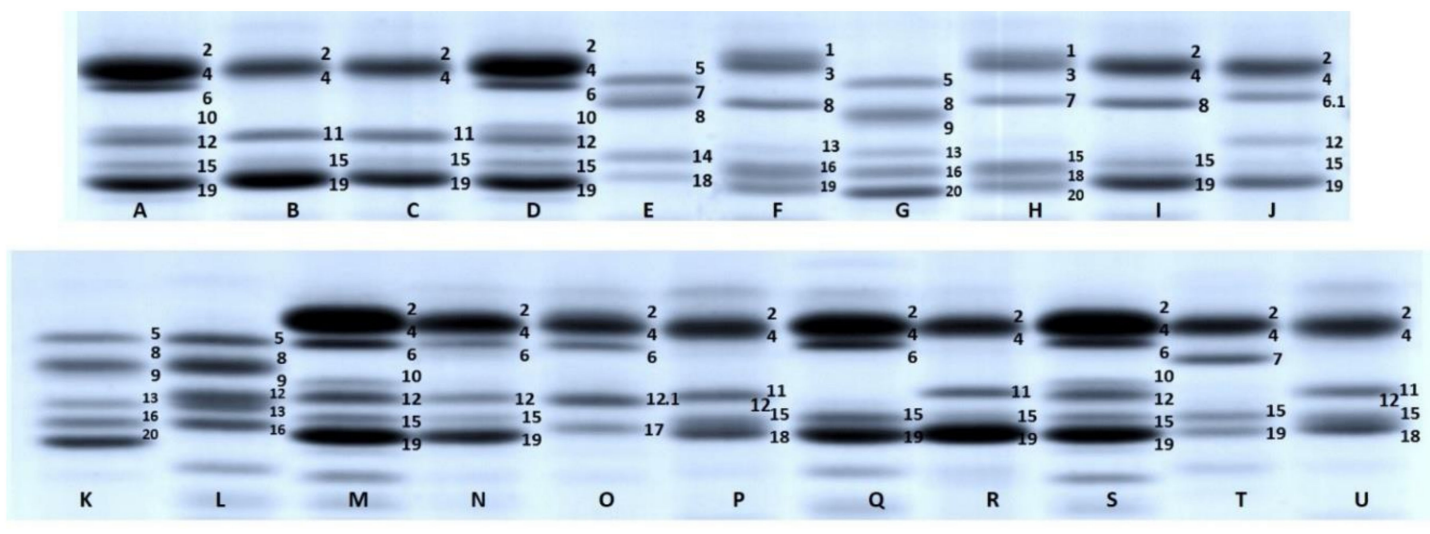

Figure 2. LMW-GS composition observed in a durum wheat collection of Moroccan landraces. Lanes are as follow: A, D, M and S, 'Cocorit' (Glu-A3 6+10, Glu-B3 2+4+15+19, Glu-B2 12); B, MGB-3091 (Glu-A3 11, Glu-B3 2+4+15+19, Glu-B2 null); C, MGB-5967 (Glu-A3 11, Glu-B3 2+4+15+19, Glu-B2 null); E, 'Andalusia' (Glu-A3 5, Glu-B3 7+8+14+18, Glu-B2 null); F, MGB-3152 (Glu-A3 null, Glu-B3 1+3+8+13+16+19, Glu-B2 null); G and K, 'Fanfarron' (Glu-A3 5+20, Glu-B3 8+9+13+16, Glu-B2 null); H, MGB-16563 (Glu-A3 20, Glu-B3 1+3+7+15+18, Glu-B2 null); I, MGB-2963 (Glu-A3 null, Glu-B3 2+4+8+15+19, Glu-B2 null); J, 'BC' (Glu-A3 6.1, Glu-B3 2+4+15+19, Glu-B2 12); L, MGB-3104 (Glu-A3 5, Glu-B3 8+9+13+16, Glu-B2 12); N, MGB-3083 (Glu-A3 6, Glu-B3 2+4+15+19, Glu-B2 12); O, MGB-3125 (Glu-A3 6, Glu-B3 2+4+17, Glu-B2 12.1); P and U, 'Ardente' (Glu-A3 11, Glu-B3 2+4+15+18, Glu-B2 12); Q, MGB-9430 (Glu-A3 6, Glu-B3 2+4+15+19, Glu-B2 null); R, MGB-3003 (Glu-A3 11, Glu-B3 2+4+15+19, Glu-B2 null); T, MGB-5963 (Glu-A3 null, Glu-B3 2+4+7+15+19, Glu-B2 null).

The group of Moroccan cultivars showed five alleles at the Glu-A3 locus. Alleles Glu-A3a and Glu-A3e were the most frequent, being present in $42.9 \%$ and $28.6 \%$ of the accessions in this set, respectively. One accession (MGB-20) exhibited a novel subunit that we have tentatively named $5^{* *}$. This subunit has a slightly higher mobility than the subunit 5 present in 'Fanfarron' (Figure 3-I, lanes A and B). This allele was named Glu-A3bc here. At the Glu-B3 locus, only two alleles were identified: Glu-B3a, which was present in $78.6 \%$ of the Moroccan cultivars, and allele Glu-B3ah, which was present in three cultivars. At the Glu-B2 locus, both the alleles Glu-B2a, Glu-B2b and the novel allele Glu-B2d were identified.

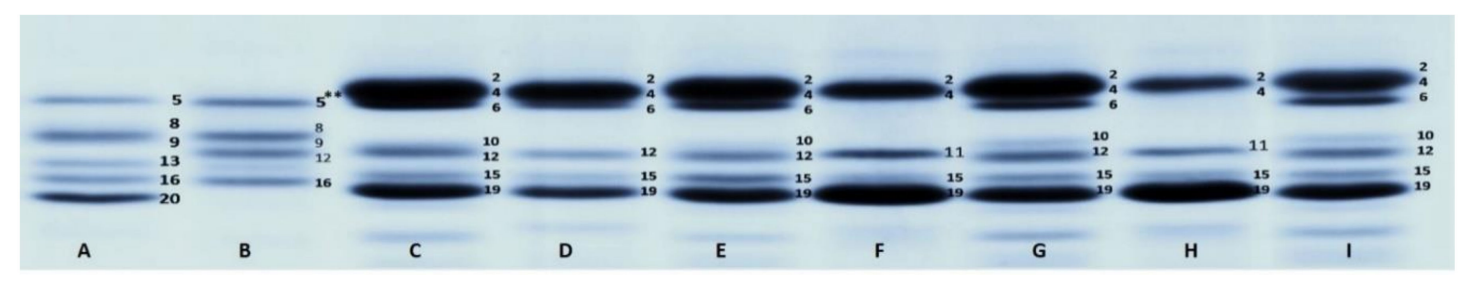

Figure 3. LMW-GS composition observed in a durum wheat set of Moroccan cultivars. Lanes are as follow: A, 'Fanfarron' (Glu-A3 5+20, Glu-B3 8+9+13+16, Glu-B2 null); B, MGB-20 (Glu-A3 5**, Glu-B3 8+9+16, Glu-B2 12); C, G and I, 'Cocorit' (Glu-A3 6+10, Glu-B3 2+4+15+19, Glu-B2 12); D, MGB-32 (Glu-A3 6, Glu-B3 2+4+15+19, Glu-B2 12); E, MGB-27 (Glu-A3 6+10, Glu-B3 2+4+15+19, Glu-B2 12); F, MGB-29 (Glu-A3 11, Glu-B3 2+4+15+19, Glu-B2 null); H, MGB-33 (Glu-A3 11, Glu-B3 2+4+15+19, Glu-B2 null).

Finally, among the North American cultivars, no rare or novel LMW-GS alleles were identified, except for the allele Glu-B3ah found in the accession MGB-66065. Apart from that, the most common Glu-A3, Glu-B3 and Glu-B2 alleles were Glu-A3a (69\%), Glu-B3a (89.7\%) and Glu-B2a (72.4\%), respectively. 


\subsection{Genetic Diversity}

The genetic diversity was estimated for both the whole set of the analyzed material and for each subgroup (Table 3). As expected, the Moroccan landraces were the most diverse, as indicated by the high mean value for the effective number of alleles $(\mathrm{Ne})$ and for the genetic diversity $(\mathrm{He})$ (Table 3). Across the three groups, a higher diversity was observed for the Glu-B1 locus, whereas the locus Glu-A1 was almost homogenous and had the lowest values for all three sub-collections. Among the LMW-GS, the Glu-A3 locus was associated with the highest values of diversity in all three groups, even though a greater number of alleles were identified at the Glu-B3 locus.

Table 3. Number of alleles and of glutenins patterns, and genetic diversity parameters.

\begin{tabular}{|c|c|c|c|c|}
\hline Group & Locus & $A$ & $\mathrm{Ne}$ & $\mathrm{He}$ \\
\hline \multirow{7}{*}{ Total } & Glu-A1 & 2 & 1.022 & 0.022 \\
\hline & Glu-B1 & 7 & 4.231 & 0.764 \\
\hline & Glu-D1 & 1 & 1.043 & 0.041 \\
\hline & Glu-A3 & 8 & 3.368 & 0.323 \\
\hline & Glu-B3 & 10 & 1.504 & 0.335 \\
\hline & Glu-B2 & 3 & 1.919 & 0.479 \\
\hline & Mean & 5.16 & 2.181 & 0.327 \\
\hline \multirow{6}{*}{ Moroccan landraces } & Glu-A1 & 2 & 1.039 & 0.037 \\
\hline & Glu-B1 & 6 & 3.516 & 0.716 \\
\hline & Glu-A3 & 6 & 2.922 & 0.657 \\
\hline & Glu-B3 & 9 & 1.668 & 0.400 \\
\hline & Glu-B2 & 3 & 2.076 & 0.518 \\
\hline & Mean & 5.2 & 2.244 & 0.465 \\
\hline \multirow{6}{*}{ Moroccan cultivars } & Glu-A1 & 1 & 1 & 0 \\
\hline & Glu-B1 & 4 & 3.377 & 0.704 \\
\hline & Glu-A3 & 5 & 3.374 & 0.703 \\
\hline & Glu-B3 & 2 & 1.579 & 0.366 \\
\hline & Glu-B2 & 2 & 1.324 & 0.245 \\
\hline & Mean & 2.8 & 2.131 & 0.404 \\
\hline \multirow{7}{*}{ North American cultivars } & Glu-A1 & 1 & 1 & 0 \\
\hline & Glu-B1 & 4 & 2.088 & 0.521 \\
\hline & Glu-D1 & 1 & 1.123 & 0.11 \\
\hline & Glu-A3 & 4 & 1.941 & 0.485 \\
\hline & Glu-B3 & 4 & 1.237 & 0.192 \\
\hline & Glu-B2 & 2 & 0.166 & 0.4 \\
\hline & Mean & 2.6 & 1.259 & 0.284 \\
\hline
\end{tabular}

A: number of alleles; Ne: effective number of alleles; He: Nei's genetic diversity.

The number of different patterns of glutenins combinations based on the variability described for the six glutenin loci was also calculated. In total, twenty-nine different combinations of glutenins were found in the analyzed materials, which indicates that almost all the accessions within each of the three subgroups (Moroccan landraces, Moroccan cultivars and North American cultivars) had a unique glutenin pattern. Specifically, the group of the Moroccan landraces showed the highest number of glutenins combinations (21), followed by the North American cultivars (12) and the Moroccan landraces (9) (Electronic Supplementary Table S1).

\section{Discussion}

Glutenins are probably the most studied among the wheat grain proteins, due to the association of their variability with processing and end-use quality traits $[10,14,32]$. The analysis of the glutenin allelic variation among the genotypes used in breeding programs is a key and efficient tool to fully exploit all the genetic variability that is available to improve wheat quality. Besides, the efficient use of a germplasm collection can only be effective if enough knowledge of the genetic variation within the 
collection for the specific traits of interest is available [33]. Morocco is an important wheat consumer (consumption is around $220 \mathrm{~kg}$ per capita per year); however, a significant quantity of the wheat is imported (common wheat and durum wheat imports were valued at 710 and 255 USD million, respectively, in 2019). For this reason, in order to reduce the dependence from the wheat imports and strengthen food security in the country, great efforts from the Moroccan breeding community are needed in order to develop new competitive wheat varieties with a desirable quality in order to elaborate traditional products but also new cultivars with a grain quality accepted by the modern processing industry. In this context, the set of durum wheat materials analyzed here could serve as a precious genetic resource to reach this goal. The accessions analyzed in this study could be divided into three groups: (1) landraces from Morocco, which is part of one of the durum wheat centers of diversity (North Africa) [34]; (2) modern Moroccan cultivars, which are the results of the work of the CIMMYT, ICARDA and national breeding programs; and (3) a set of modern cultivars from North America, probably held in the Germplasm Bank to enhance the genetic diversity in local breeding programs and improve grain quality. Canada and USA are, in fact, durum wheat exporters to Morocco, and their germplasm typically meets the quality standards demanded by the Moroccan wheat modern processing industry. However, for more traditional products, landraces or local cultivars are preferred. Therefore, their analysis is necessary to determine the quality traits associated with an optimal adaptation for these traditional foods.

Several alleles were found for each of the glutenins loci. Within the HMW-GS group, at the Glu-A1 locus, only one landrace showed a non-null allele, which is relatively normal, as most modern durum wheat materials typically exhibit the null allele at this locus [35-38]. However, other sets of durum wheat landraces have shown higher frequencies for Glu-A1 alleles different from the Glu-A1c null allele $[19,20,39]$. The contribution of the non-null $G l u-A 1$ alleles to durum wheat quality traits is still not well defined. Some studies indicate that these alleles probably do not have a significant effect on durum wheat gluten quality $[10,19,40]$, whereas other studies clearly show that their presence enhances gluten strength and extensibility [41-43]. The Glu-B1 locus showed the highest number of alleles (7). Among them, two were novel and were found in one North American accession (Glu-B1cp, subunit 20*) and two Moroccan landraces (Glu-B1co, subunits 20+22*). Among the other identified Glu-B1 alleles, Glu-B1b, Glu-B1d and Glu-B1e were the most frequent $(17.9 \%, 28.4 \%$ and $26.3 \%$, respectively), in agreement with previous results obtained from the analysis of different durum wheat collections $[24,34,39,44,45]$. These results are also in agreement with the ones obtained by Zarkti et al. [11] from the analysis of a different set of durum wheat accessions from the same Germplasm Bank. According to previous studies, alleles Glu-B1b and Glu-B1d have been associated to different extents to a high gluten strength $[10,35,38]$, whereas allele Glu-B1e has been linked to a low gluten quality $[35,46-48]$, probably because of the substitution of two cysteine residues with tyrosine at the N-terminus [49]. However, Nazco et al. [10] could not associate Glu-B1e with a low gluten quality. The other Glu-B1 allele identified here, Glu-B1aq (32+33), showed a remarkably high frequency compared with other sets of durum materials. This rare allele was originally found in an emmer wheat accession (CI-12213) by Cherdouh et al. [22] and later in some Spanish landraces [19] and in some durum wheat landraces from Iran [9], even at lower frequencies than in this study. Chacón et al. [19] found that this allele may be associated with lower gluten strength, whereas Hernández-Espinosa et al. [9] associated this allele with a higher gluten strength, extensibility and bread-making quality. However, it has to be noted that both studies reported preliminary results and that more work is needed in order to define the effects of this allele on quality traits. In addition to this, two of the cultivars from the North American set showed the presence of the Glu-D1d subunits 5+10, which are typically present in the D-genome from bread wheat. One of these accessions (UCRD01-1) was developed by chromosome engineering [50], and the other (Westbred 1000D) is most likely derived from a similar material from the same authors, but it has probably been wrongly registered in the Germplasm Bank. The introgression of the Glu-D1 locus in durum wheat varieties has been shown to greatly increase gluten strength, 
even though, for the enhancement of the durum wheat bread-making quality, the Glu-D1a allele (subunits 2+12) appeared to be more promising compared to allele Glu-D1d [51,52].

Great variability was also found for the LMW-GS loci, which have a more important role in durum wheat quality than the HMW-GS. Several novel subunits were identified, and, based on their similarity with previously identified subunits/alleles, they were tentatively assigned to specific LMW-GS loci and given a unique allele nomenclature according to the guidelines reported in the Wheat Gene Catalogue. Recently, recombination has been reported in some of the LMW glutenin Glu-3 loci [53], which could also affect allele nomenclature. At the Glu-A3 locus, alleles $G l u-A 3 a$ and $G l u-A 3 e$ were the most frequent, in accordance with other studies that also reported the predominance of the Glu-A3a $[19,22,27,39,45]$ and Glu-A3e [54] alleles within different sets of durum wheat accessions. According to previous studies, the Glu-A3a and Glu-A3e alleles have been associated with stronger and weaker gluten, respectively. Apart from this, one rare and one novel allele were also identified: Glu-A3bb (subunit 20) and Glu-A3bc (subunit $5^{* *}$ ). Their effect on gluten quality will need to be more thoroughly investigated. At the Glu-B3 locus, ten different alleles were detected, and of these, five were novel (Glu-B3ar, subunits $1+3+7+15+18$; Glu-B3as, subunits $1+3+8+13+16+19$; Glu-B3at, subunits $2+4+17$; Glu-B3au, subunits $2+4+7+15+19$; and Glu-B3av, subunits $9+13+16$ ). Most of these novel alleles were each present in only a single landrace accession, thus emphasizing the importance of safeguarding these materials in Germplasm Banks to prevent the loss of genetic diversity. Furthermore, in this case, more studies are needed to understand the role of these alleles on durum wheat quality. The prevalence of the allele $G l u-B 3 a$ among the $G l u-B 3$ alleles is probably due to its relation with superior durum wheat end-use quality, as indicated by several previous studies [43,46,48]. Finally, at the Glu-B2 locus, three different alleles were identified, and, as expected, the allele Glu-B2a was the most frequent $[9,22,55]$. The only exceptions were the Moroccan landraces, among which the alleles Glu-B2a and Glu-B2b were equally represented. Similar results were obtained for other sets of landraces, as reported by Nazco et al. [10] and Chacón et al. [19]. Among the three alleles detected at the Glu-B2 locus, the allele Glu-B2d (subunit 12.1) was reported here for the first time.

The level of genetic diversity for glutenins found in this collection $(\mathrm{He}=0.327)$ varied within the three sub-groups that were analyzed, with the landraces showing the highest values $(\mathrm{He}=0.465)$, followed by the Moroccan and North American cultivars ( $\mathrm{He}=0.404$ and 0.284 , respectively). The reduction of the genetic diversity in modern wheat cultivars is a global common trend, which needs, however, to be inverted in order to ensure a continuous improvement in the newly developed varieties. As a matter of fact, the results reported in this study show that few rare alleles from the pool of landraces have been transferred to the modern cultivars pool and that most of the rare alleles are only present in the landraces set, which illustrates well the loss of variability observed in modern cultivars due to genetic erosion. The genetic variability found in the group of Moroccan landraces could be considered average if we compare our results with similar studies done in other countries of the Mediterranean region. Aguiriano et al. [20] found a higher diversity than in our study in Spanish landraces $(\mathrm{He}=0.72)$, as did Moragues et al. [23] $(\mathrm{He}=0.67)$ in a more heterogenous collection with materials from different Mediterranean countries. Bellil et al. [39] also found a high diversity in landraces from Algerian oases. On the other hand, Igrejas et al. [56] and Hamdi et al. [57] reported lower levels of diversity ( $\mathrm{He}=0.36$ and 0.34 , respectively) in Portuguese and Algerian materials, respectively.

\section{Conclusions}

Extensive variation at the glutenins loci has been found among a set of durum wheat materials conserved in the Moroccan Germplasm Bank, particularly in a set of old Moroccan landraces. In total, nine novel alleles (two for Glu-B1, one for Glu-A3, five for Glu-B3 and one for Glu-B2) were reported in the different materials that were analyzed, enhancing the significance of preserving and characterizing these materials. This characterization of genetic resources is useful for the development of new varieties with quality traits appreciated by local consumers and the industry. The study opens the possibility for further research aiming to investigate the effects on quality traits of the described variation, including 
the specific effects of rare and novel alleles as well as the effects of novel combinations of alleles found among these materials.

Supplementary Materials: The following are available online at http://www.mdpi.com/2073-4395/10/7/957/s1. Electronic Supplementary Table S1: Glutenins composition of 95 durum wheat accessions of the Moroccan Germplasm Bank.

Author Contributions: Investigation, formal analysis, writing-Original draft, Y.C.; resources, conceptualization, writing-Review \& editing, H.O.; resources, conceptualization, writing-Review \& editing. A.E.; investigation, F.C.; resources, writing — Review \& editing, M.I.I.; resources, conceptualization, supervision, writing — Review \& editing, C.G. All authors have read and agreed to the published version of the manuscript.

Funding: This research was funded by the CRP-Wheat program of the CGIAR consortium, the University of Hassan 1st Settat (Morocco), the ICARDA/Morocco program of collaboration for collaboration on the conservation and use of plant genetic resources (MCGP).

Acknowledgments: The authors greatly appreciate the financial support of Carlos Guzman gratefully acknowledges the European Social Fund and the Spanish State Research Agency (Ministry of Science, Innovation and Universities) for financial funding through the Ramon y Cajal Program (RYC-2017-21891).

Conflicts of Interest: The authors declare no conflict of interest.

\section{References}

1. Feuillet, C.; Langridge, P.; Waugh, R. Cereal breeding takes a walk on the wild side. Trends Genet. 2008, 24, 24-32. [CrossRef] [PubMed]

2. Nsarellah, N.; Amamou, A.; Taghouti, M.; Annicchiarico, P. Adaptation of Moroccan durum wheat varieties from different breeding eras. J. Plant. Breed. Crop. Sci. 2011, 3, 34-40.

3. Taghouti, M.; Rhrib, K.; Gaboun, F. Exploiting landrace genetic diversity for germplasm enhancement in durum wheat breeding in Morocco. In Proceedings of the International Symposium on Genetics and Breeding of Durum Wheat, Rome, Italy, 27-30 May 2013.

4. Cam, D. Global Durum Outlook. 2017. Available online: http://www.italmopa.com/wp-content/uploads/ 2017/05/144_all_1.pdf (accessed on 25 January 2020).

5. Ramdani, A.; Ouabbou, H.; Nsarellah, N.; Lhaloui, S.; Abbad-Andaloussi, F.; Nachit, M.M.; Bhavani, S.; Nazari, K.; Wanyera, R.; Ferrahi, M.; et al. The strategies to serve and conserve Moroccan durum wheat genetic diversity before it is lost. In Proceedings of the International Symposium on Genetics and Breeding of Durum Wheat, Rome, Italy, 27-30 May 2013; CIHEAM (Options Méditerranéennes: Série A. Séminaires, Méditerranéens; n., 110); Porceddu, E., Damania, A.B., Qualset, C.O., Eds.; CIHEAM: Bari, Italy, 2014; pp. 131-138.

6. Amallah, L.; Taghouti, M.; Rhrib, K.; Gaboun, F.; Arahou, M.; Hassikou, R.; Diria, G. Validation of simple sequence repeats associated with quality traits in durum wheat. J. Crop. Sci. Biotechnol. 2016, 19, 137-150. [CrossRef]

7. Sahri, A.; Chentoufi, L.; Arbaoui, M.; Ardisson, M.; Belqadi, L.; Birouk, A.; Roumet, P.; Muller, M.H. Towards a comprehensive characterization of durum wheat landraces in Moroccan traditional agrosystems: Analysing genetic diversity in the light of geography, farmers' taxonomy and tetraploid wheat domestication history. BMC Evol. Biol. 2014, 14. [CrossRef]

8. Chentoufi, L.; Sahri, A.; Arbaoui, M.; Belqadi, L.; Birouk, A.; Roumet, P.; Muller, M.H. Anchoring durum wheat diversity in the reality of traditional agricultural systems: Varieties, seed management, and farmers' perception in two Moroccan regions. J. Ethnobiol. Ethnomed. 2014, 10, 58. [CrossRef] [PubMed]

9. Hernández-Espinosa, N.; Payne, T.; Huerta-Espino, J.; Cervantes, F.; Gonzalez-Santoyo, H.; Ammar, K.; Guzmán, C. Preliminary characterization for grain quality traits and high and low molecular weight glutenins subunits composition of durum wheat landraces from Iran and Mexico. J. Cereal Sci. 2019, 88, 47-56. [CrossRef]

10. Nazco, R.; Peña, R.J.; Ammar, K.; Villegas, D.; Crossa, J.; Moragues, M.; Royo, C. Variability in glutenin subunit composition of Mediterranean durum wheat germplasm and its relationship with gluten strength. J. Agric. Sci. 2014, 152, 379-393. [CrossRef]

11. Zarkti, H.; Ouabbou, H.; Taghouti, M.; Hilali, A.; Udupa, S.M. Comparison of genetic diversity at prolamin loci in Moroccan durum wheat accessions. Plant Omics 2010, 3, 154-158. 
12. Morgounov, A.; Keser, M.; Kan, M.; Küçükçongar, M.; Özdemir, F.; Gummadov, N.; Muminjanov, H.; Zuev, E.; Qualset, C.O. Wheat landraces currently grown in Turkey: Distribution, diversity, and use. Crop Sci. 2016, 56, 3112-3124. [CrossRef]

13. Singh, N.K.; Shepherd, K.W.; Cornish, G.B. A simplified SDS-PAGE procedure for separating LMW subunits of glutenin. J. Cereal Sci. 1991, 14, 203-208. [CrossRef]

14. Carrillo, J.M.; Martínez, M.C.; Brites, M.C.; Nieto-Taladriz, M.T.; Vázquez, J.F. Relationship between endosperm proteins and quality in durum wheat (Triticum turgidum L. var. durum). In Durum Wheat Quality in the Mediterranean Region: New Challenges; Royo, C., Nachit, M., Di Fonzo, N., Araus, J.L., Eds.; CIHEAM (Options Méditerranéennes: Série A. Séminaires Méditerranéens; n. 40); CIHEAM: Zaragoza, Spain, 2000; pp. 463-467.

15. Payne, P.I.; Holt, L.M.; Law, C.N. Structural and genetical studies on the high-molecular-weight subunits of wheat glutenin. Theor. Appl. Genet. 1981, 60, 229-236. [CrossRef] [PubMed]

16. Shewry, P.R.; Halford, N.G.; Tatham, A.S. High molecular weight subunits of wheat glutenin. J. Cereal Sci. 1992, 15, 105-120. [CrossRef]

17. Vázquez, J.F.; Ruiz, M.; Nieto-Taladriz, M.T.; Albuquerque, M.M. Effects on gluten strength of low Mr glutenin subunits coded by alleles at Glu-A3 and Glu-B3 loci in durum wheat. J. Cereal Sci. 1996, 24, 125-130. [CrossRef]

18. Carrillo, J.M.; Vazquez, J.F.; Orkellana, J. Relationship between gluten strength and glutenin proteins in durum wheat cultivars. Plant Breed. 1990, 104, 325-333. [CrossRef]

19. Chacón, E.A.; Vázquez, F.J.; Giraldo, P.; Carrillo, J.M.; Benavente, E.; Rodríguez-Quijano, M. Allelic variation for prolamins in Spanish durum wheat landraces and its relationship with quality traits. Agronomy 2020, 10, 136. [CrossRef]

20. Aguiriano, E.; Ruiz, M.; Fité, R.; Carrillo, J.M. Genetic variation for glutenin and gliadins associated with quality in durum wheat (Triticum turgidum L. ssp. turgidum) landraces from Spain. Span. J. Agric. Res. 2008, 6, 599. [CrossRef]

21. Babay, E.; Hanana, M.; Mzid, R.; Slim-Amara, H.; Carrillo, J.M.; Rodríguez-Quijano, M. Influence of allelic prolamin variation and localities on durum wheat quality. J. Cereal Sci. 2015, 63, 27-34. [CrossRef]

22. Cherdouh, A.; Khelifi, D.; Carrillo, J.M.; Nieto-Taladriz, M.T. The high and low molecular weight glutenin subunit polymorphism of Algerian durum wheat landraces and old cultivars. Plant Breed. 2005, 124, 338-342. [CrossRef]

23. Moragues, M.; Zarco-Hernández, J.; Moralejo, M.A.; Royo, C. Genetic diversity of glutenin protein subunits composition in durum wheat landraces [Triticum turgidum ssp. turgidum Convar. durum (Desf.) MacKey] from the Mediterranean Basin. Genet. Resour. Crop. Evol. 2006, 53, 993-1002. [CrossRef]

24. Ruiz, M.; Bernal, G.; Giraldo, P. An update of low molecular weight glutenin subunits in durum wheat relevant to breeding for quality. J. Cereal Sci. 2018, 83, 236-244. [CrossRef]

25. Peña, R.J.; Gonzalez-Santoyo, H.; Cervantes, F. Relationship between Glu-D1/Glu-B3 allelic combinations and bread-making quality-related parameters commonly used in wheat breeding. In The Gluten Proteins. Proceedings of the 8th Gluten Workshop, Viterbo, Italy, 8-10 September 2003; Masci, S., Lafiandra, D., D'Ovidio, R., Eds.; Royal Society of Chemistry: Cambridge, UK, 2003; pp. 156-157.

26. Payne, P.I.; Lawrence, G.J. Catalogue of alleles for the complex gene loci, Glu-A1, Glu-B1, and Glu-D1 which code for high-molecular-weight subunits of glutenin in hexaploid wheat. Cereal Res. Commun. 1983, 11, 29-35.

27. Nieto-Taladriz, M.T.; Ruiz, M.; Martínez, M.C.; Vázquez, J.F.; Carrillo, J.M. Variation and classification of B low-molecular-weight glutenin subunit alleles in durum wheat. Theor. Appl. Genet. 1997, 95, 1155-1160. [CrossRef]

28. Nei, M. Genetic distance between populations. Am. Nat. 1972, 106, 283-292. [CrossRef]

29. Nei, M. Analysis of gene diversity in subdivided populations. Proc. Natl. Acad. Sci. USA 1973, 70, $3321-3323$. [CrossRef]

30. McIntosh, R.A.; Dubcovsky, J.; Rogers, W.J.; Morris, C.; Appels, R.; Xia, X.C. Catalogue of Gene Symbols for Wheat. 2011. Available online: https://shigen.nig.ac.jp/wheat/komugi/genes/macgene/supplement2011.pdf (accessed on 25 October 2019).

31. Alvarez, J.B.; Guzmán, C. Recovery of wheat heritage for traditional food: Genetic variation for high molecular weight glutenin subunits in neglected/underutilized wheat. Agronomy 2019, 9, 755. [CrossRef] 
32. Sissons, M.J.; Ames, N.P.; Hare, R.A.; Clarke, J.M. Relationship between glutenin subunit composition and gluten strength measurements in durum wheat. J. Sci. Food Agric. 2005, 85, 2445-2452. [CrossRef]

33. Sorrells, M.E.; Nachit, M.M.; Ketata, H. Relationships among 81 durum genotypes based RFLPs, gliadins, parentage, and quality traits. In Durum Wheat Quality in the Mediterranean Region; Di Fonzo, N., Kaan, F., Nachit, M., Eds.; CIHEAM (Options Méditerranéennes: Série A. Séminaires Méditerranéens; n. 22); CIHEAM: Zaragoza, Spain, 1995; pp. 249-262.

34. Janni, M.; Cadonici, S.; Bonas, U.; Grasso, A.; Dahab, A.A.D.; Visioli, G.; Pignone, D.; Ceriotti, A.; Marmiroli, N. Gene-ecology of durum wheat HMW glutenin reflects their diffusion from the center of origin. Sci. Rep. 2018, 8, 16929. [CrossRef]

35. Ammar, K.; Kronstad, W.E.; Morris, C.F. Breadmaking quality of selected durum wheat genotypes and its relationship with high molecular weight glutenin subunits allelic variation and gluten protein polymeric composition. Cereal Chem. 2000, 77, 230-236. [CrossRef]

36. Branlard, G.; Autran, J.C.; Monneveux, P. High molecular weight glutenin subunit in durum wheat (T. durum). Theor. Appl. Genet. 1989, 78, 353-358. [CrossRef]

37. Henkrar, F.; El-Haddoury, J.; Iraqi, D.; Bendaou, N.; Udupa, S.M. Allelic variation at high-molecular weight and low-molecular weight glutenin subunit genes in Moroccan bread wheat and durum wheat cultivars. 3 Biotech 2017, 7, 287. [CrossRef] [PubMed]

38. Magallanes-López, A.M.; Ammar, K.; Morales-Dorantes, A.; González-Santoyo, H.; Crossa, J.; Guzmán, C. Grain quality traits of commercial durum wheat varieties and their relationships with drought stress and glutenins composition. J. Cereal Sci. 2017, 75, 1-9. [CrossRef]

39. Bellil, I.; Chekara Bouziani, M.; Khelifi, D. Genetic diversity of high and low molecular weight glutenin subunits in Saharan bread and durum wheats from Algerian oases. Czech J. Genet. Plant Breed. 2012, 48, 23-32. [CrossRef]

40. Uthayakumaran, S.; Beasley, H.L.; Stoddard, F.L.; Keentok, M.; Phan-Thien, N.; Tanner, R.I.; Békés, F. Synergistic and additive effects of three high molecular weight glutenin subunit loci. I. Effects on wheat dough rheology. Cereal Chem. 2002, 79, 294-300. [CrossRef]

41. Boggini, G.; Tusa, P.; Pogna, N.E. Bread making quality of durum wheat genotypes with some novel glutenin subunit compositions. J. Cereal Sci. 1995, 22, 105-113. [CrossRef]

42. Dhaliwal, H.S.; Garg, M.; Singh, H.; Chhuneja, P.; Kaur, H. Transfer of HMW-glutenin subunits from wild wheats into Triticum durum and improvement of quality. Cereal Res. Commun. 2002, 30, 173-180. [CrossRef]

43. Del Carmen Martinez, M.; Ruiz, M.; Carrillo, J.M. Effects of different prolamin alleles on durum wheat quality properties. J. Cereal Sci. 2005, 41, 123-131. [CrossRef]

44. Raciti, C.N.; Doust, M.A.; Lombardo, G.M.; Boggini, G.; Pecetti, L. Characterization of durum wheat mediterranean germplasm for high and low molecular weight glutenin subunits in relation with quality. Eur. J. Agron. 2003, 19, 373-382. [CrossRef]

45. Bellil, I.; Hamdi, O.; Khelifi, D. Diversity of five glutenin loci within durum wheat (Triticum turgidum L. ssp. durum (Desf.) Husn.) germplasm grown in Algeria. Plant Breed. 2014, 133, 179-183. [CrossRef]

46. Brites, C.; Carrillo, J.M. Influence of high molecular weight (HMW) and low molecular weight (LMW) glutenin subunits controlled by Glu-1 and Glu-3 loci on durum wheat quality. Cereal Chem. 2001, 78, 59-63. [CrossRef]

47. Edwards, N.M.; Gianibelli, M.C.; McCaig, T.N.; Clarke, J.M.; Ames, N.P.; Larroque, O.R.; Dexter, J.E. Relationships between dough strength, polymeric protein quantity and composition for diverse durum wheat genotypes. J. Cereal Sci. 2007, 45, 140-149. [CrossRef]

48. Ruiz, M.; Carrillo, J.M. Relationships between different prolamin proteins and some quality properties in durum wheat. Plant Breed. 1995, 114, 40-44. [CrossRef]

49. Shewry, P.; Gilbert, S.; Savage, A.; Tatham, A.; Wan, Y.-F.; Belton, P.; Wellner, N.; D’Ovidio, R.; Békés, F.; Halford, N. Sequence and properties of HMW subunit 1Bx20 from pasta wheat (Triticum durum) which is associated with poor end use properties. Theor. Appl. Genet. 2003, 106, 744-750. [CrossRef] [PubMed]

50. Lukaszewski, A.J. Registration of six germplasms of durum wheat with introgressions of the Glu-D1 locus. Crop Sci. 2003, 43, 1138-1139. [CrossRef]

51. Morris, C.F.; Kiszonas, A.M.; Murray, J.; Boehm, J.; Ibba, M.I.; Zhang, M.; Cai, X. Re-evolution of Durum Wheat by Introducing the Hardness and Glu-D1 Loci. Front. Sustain. Food Syst. 2019, 3, 103. [CrossRef] 
52. Sissons, M.; Pleming, D.; Sestili, F.; Lafiandra, D. Effect of Glu-D1 gene introgression and amylose content on breadmaking potential of blends of durum and hexaploid wheat. Cereal Chem. 2019, 96, 193-206. [CrossRef]

53. Ibba, M.I.; Kiszonas, A.M.; Guzmán, C.; Morris, C.F. Definition of the low molecular weight glutenin subunit gene family members in a set of standard bread wheat (Triticum aestivum L.) varieties. J. Cereal Sci. 2017, 74, 263-271. [CrossRef]

54. Hu, X.; Peng, Y.; Ren, X.; Peng, J.; Nevo, E.; Ma, W.; Sun, D. Allelic variation of low molecular weight glutenin subunits composition and the revealed genetic diversity in durum wheat (Triticum turgidum L. ssp. durum (Desf)). Breed. Sci. 2018, 68, 524-535. [CrossRef]

55. Subira, J.; Peña, R.J.; Álvaro, F.; Ammar, K.; Ramdani, A.; Royo, C. Breeding progress in the pasta-making quality of durum wheat cultivars released in Italy and Spain during the 20th Century. Crop. Pasture Sci. 2014, 65, 16. [CrossRef]

56. Igrejas, G.; Guedes-Pinto, H.; Carnide, V.; Branlard, G. The high and low molecular weight glutenin subunits and $\omega$-gliadin composition of bread and durum wheats commonly grown in Portugal. Plant Breed. 1999, 118, 297-302. [CrossRef]

57. Hamdi, W.; Bellil, I.; Branlard, G.; Khelifi, D.; Street, C. Genetic Variation and geographical diversity for seed storage proteins of seventeen durum wheat populations collected in Algeria. Not. Bot. Horti Agrobot. Cluj Napoca 2010, 38, 22-32.

(C) 2020 by the authors. Licensee MDPI, Basel, Switzerland. This article is an open access article distributed under the terms and conditions of the Creative Commons Attribution (CC BY) license (http://creativecommons.org/licenses/by/4.0/). 